\title{
Luiz Beltrão e os movimentos iniciais da pesquisa em Jornalismo no Brasil
}

\section{Nayane Cristina Rodrigues de Brito ${ }^{1}$}

\section{Resumo}

Este artigo propõe refletir teoricamente alguns aspectos da história de Luiz Beltrão para a posteriori compreender sua incursão nos estudos em comunicação e especificamente as contribuições para a Teoria do Jornalismo. O texto aborda aspectos da trajetória do autor, apreensões sobre o livro Iniciação à Filosofia do Jornalismo, a trilogia - Jornalismo informativo, interpretativo e opinativo - além das ponderações de pesquisadores quanto aos estudos de Beltrão. Verifica-se que as obras do teórico relacionadas ao jornalismo estabelecem-se como as primeiras iniciativas para a constituição de uma Teoria do Jornalismo. O pesquisador formula as categorias de gêneros informativo, interpretativo e opinativo e estimula o ensino em Jornalismo.

Palavras-chave: Jornalismo. Luís Beltrão. Teoria do Jornalismo.

\section{Abstract}

This article proposes to theoretically reflect some aspects of the history of Luiz Beltrão to later understand his foray into communication studies and specifically the contributions to the Theory of Journalism. The text deals with aspects of the trajectory of the author, apprehensions about the book Initiation to the Philosophy of Journalism, the trilogy - informative, interpretative and opinionated journalism in addition to the researcher's comments about Beltrão's studies. It is verified that the works of the theoretician related to journalism establish themselves as the first initiatives for the constitution of a Theory of Journalism. The researcher formulates the categories of informative, interpretative and opinionated genres and stimulates teaching in Journalism.

Keywords: Journalism. Luís Beltrão. Theory of Journalism.

1 Doutoranda do Programa de Pós-graduação em Jornalismo da Universidade Federal de Santa Catarina (UFSC), Florianópolis, Brasil. Integra o Grupo de Investigação em Rádio, Fonografia e Áudio - GIRAFA e o Grupo de Pesquisa, Jornalismo, Mídia e Memória - JOIMP. Bolsista da Fundação de Amparo à Pesquisa e Inovação do Estado de Santa Catarina (FAPESC)/CAPES. E-mail: nayanebritojornalista@gmail.com 


\section{Beltrão: da ficção ao jornalismo}

Quando a idéia da greve começara a germinar, revelou-se não só um organizador como um teórico: estava convencido de que, na atual conjuntura e mesmo no futuro, com a avançada tecnologia da era do computador e dos robôs, seria erro histórico e fatal repetir o combate à máquina ou insistir na manutenção da política do trabalho, surgida com a Revolução Industrial (BELTRÃO, 1984, p.26).

Partir de uma situação que, por vezes, pode soar cômica e um paradoxo conceitual, uma greve de desempregados, é uma reflexão e uma crítica a sociedade capitalista. O trecho destacado no início do texto é da obra $A$ greve dos desempregados (1984), de Luiz Beltrão de Andrade Lima, um jornalista que também se permitiu escrever literatura e aproveitou para tecer críticas através dela.

O pernambucano nasceu no início do século $X X$, precisamente em oito de agosto de 1918, em Olinda. Último ano da Primeira Guerra Mundial (1914-1918) e um século marcante para a comunicação e o jornalismo brasileiro. Cita-se as primeiras experiências de rádio e TV, a inserção do lide no jornalismo impresso, alterações na linguagem do radiojornalismo na década de 1940 com o início do programa "Repórter Esso", a imprensa censurada pela terceira vez ${ }^{2}$ com a Ditadura Militar de 1964 a 1985, entre outros fatos.

Logo, este artigo propõe refletir teoricamente alguns aspectos da história de Luiz Beltrão para a posteriori compreender sua incursão nos estudos em comunicação e especificamente as contribuições para a Teoria do Jornalismo. A trajetória desse jornalista, professor, escritor, sindicalista, pesquisador e um dos teóricos pioneiro nos estudos em jornalismo está diretamente relacionada com suas produções científicas.

O seminário de Olinda foi o local em que Beltrão obteve sua primeira formação cultural. "Ali principiei a estudar e a escrever. Nessa época de Seminário, eu escrevi num caderno um romance chamado O Aimoré. Era uma réplica de O Guarani, de José de

\footnotetext{
${ }^{2} \mathrm{~A}$ imprensa brasileira já surge censurada pela coroa portuguesa. Após a implantação do Estado Novo, com Getúlio Vargas, pela segunda vez os veículos de comunicação passam a ser censurados. A terceira vez ocorre durante os 21 anos de Ditadura Militar (HOHLFELDT; VALLES, 2008).
} 
Alencar" (CANDENGUE, et al., 1987, p. 6). Recorda o teórico em entrevista a José Marques de Melo, Carlos Eduardo Lins da Silva, Rogério Bastos Cadengue e Marta Alves D'Azeveto, membros da equipe do Boletim Intercom em 1980. A entrevista foi publicada somente em 1987 pela Revista Brasileira de Ciências da Comunicação ${ }^{3}$.

O jornalista inicia no ambiente religioso a sensibilidade para a literatura e a percepção de um mundo exterior aquela atmosfera religiosa. Vale destacar que alguns contos escritos por ele aludem aspectos da igreja, a exemplo $O$ penitente, uma narrativa que retrata as obrigações e dilemas relacionados a vida de um padre. A ficção também está presente nas obras Os senhores do mundo (1950), Quilômetro zero (1961), As sombras do ciclone (1968), A serpente no atalho (1974), Contos de Olanda (1985), entre outras produções literárias. A tese de Dias (2008) apresenta aspectos da análise literária dos livros de Luiz Beltrão.

Em meio a ditadura do Estado Novo, com Getúlio Vargas (1937-1946), Beltrão começa os estudos em Ciências Jurídicas pela Faculdade de Direito do Recife. Os conhecimentos adquiridos e a convivência com os colegas corroboraram na formação intelectual do jornalista, "[...] era uma turma interessada nos problemas e fazia política possível à época" (CANDENGUE, et al., 1987, p. 6). Logo, para o cientista jurídico a faculdade não era as aulas ou os professores, "A Faculdade de Direito do Recife, para mim, eram os corredores onde haviam os famosos bancos de madeira e ferro que jamais o calouro poderia sentar no encosto, só os veteranos" (CANDENGUE, et al., 1987, p. 6). Uma percepção da importância de compreender os meandros sociais, políticos e econômicos por meio do que está além dos muros da faculdade.

O jornalismo passou a fazer parte das experiências do teórico em 1936 ao principiar suas atividades como revisor no Diário de Pernambuco, no impresso atuou nas funções de arquivista de clichê, tradutor de telegrama e repórter. Durante 17 anos esteve no Diário da Manhã, chegando a função de redator-chefe. A experiência jornalística ampliou-se com a atuação nas agências noticiosas France Press e Asa Press, operando como correspondente de agências nacionais e internacionais. Ressalta-se também experiências em revistas, rádio, assessoria de imprensa, passagens pelo Departamento de Imprensa e Propaganda, pela presidência da Associação de Imprensa de Pernambuco

${ }_{3}^{3}$ A entrevista completa está disponível em:

http://portcom.intercom.org.br/revistas/index.php/revistaintercom/article/view/1513/1492. Acessada em 09 de dezembro de 2018. 
e participação na criação do Sindicato dos Jornalistas Profissionais do seu estado (CANDENGUE, et al., 1987); (GOBBI, 2005); (WANDERLEY, 2003).

Melo (2003), relembra o pioneirismo de Beltrão na condição do primeiro doutor em Comunicação conquistado em universidade brasileira, em 1967, com a tese Folkcomunicação, um estudo dos agentes e dos meios populares de informação de fatos e expressão de ideias. Em 1971 a pesquisa é publicada em forma de livro e amplia o título para Comunicação e Folclore.

$\mathrm{Na}$ atividade de professor, ele começa na Faculdade de Filosofia Nossa Senhora de Lourdes, em João Pessoa, Paraíba, ao lecionar a disciplina de Ética e Técnica do Jornalismo. Elaborou o projeto para a criação do primeiro Curso Superior de Jornalismo, na Universidade Católica de Pernambuco, implementado em 1961. Esteve também na Universidade de Brasília (UNB) na direção do departamento de Comunicação, foi docente e pesquisador no Centro de Estudos Universitários (CEUB), (MELO, 2003).

Foram muitos cursos, eventos, palestras, pesquisas e livros publicados. Uma trajetória de pesquisa lembrada em dezenas de monografias, dissertações, artigos e teses. Fátima Feliciano é uma das primeiras pesquisadoras a estudar sobre a vida e obra de Beltrão, resultando na tese Luiz Beltrão: um senhor do mundo, defendida em 1993, na Escola de Comunicações e Artes da Universidade de São Paulo. Para Feliciano (2008) ele era um senhor "do jornalismo ... da comunicação .... e, por quê não, da Folkcomunicação...".

Gobbi (2005, p.3) o intitulou de um homem à frente de seu tempo pela capacidade profissional, atuação intelectual e o pioneirismo: "Toda sua carreira foi marcada pela inovação, espírito de luta, responsabilidade e determinação”. Além de ser o primeiro doutor em comunicação, montar o primeiro curso de jornalismo, também inovou por colaborar na criação do Instituto de Ciências da Informação (ICINFORM), e na primeira revista acadêmica de comunicação editada no Brasil, a Comunicação e Problemas, com edição inicial publicada em março de 1965.

Ele deixou uma importante produção acadêmica e literária. Além de seus vinte livros, diversas apostilas e artigos, organizou os currículos de diversas faculdades por todo Brasil, ministrou cursos nas áreas do jornalismo, relações públicas, opinião pública e ensino de comunicação. Dedicou sua vida ao ensinar, aprender e discutir jornalismo, sua grande paixão intelectual. (GOBBI, 2005, p. 03) 
Um legado reconhecido pela comunidade acadêmica e Sociedade Brasileira de Estudos Interdisciplinares da Comunicação (INTERCOM) ao instituir em 1997 o prêmio anual Luiz Beltrão de Ciências da Comunicação. Uma premiação que reconhece o trabalho de pesquisadores e instituições em pesquisas consideradas de destaques na área da comunicação.

Em 2018 comemora-se o centenário de Luiz Beltrão, um momento oportuno para refletir sobre os primeiros estudos no campo do jornalismo a partir das iniciativas desse teórico. Após essa introdução, o artigo aborda em um segundo momento as contribuições do jornalista no incentivo para a formação e qualificação profissional; o terceiro tópico foca nas produções e contribuições do pesquisador para os estudos em jornalismo; por último verifica-se as percepções de outros teóricos quanto as investigações de Beltrão que perpassam as áreas da Comunicação e Jornalismo.

\section{O professor de Jornalismo}

A docência, conforme mencionado, também fez parte da trajetória do jornalista. Melo (2003), coorientado por Beltrão durante o doutorado, considera a prática docente utilizada pelo teórico como uma pedagogia inovadora, "Minha tese de doutorado em Jornalismo (defendida em 1973) fundamentou-se em muitas idéias desenvolvidas por Luiz Beltrão" (MELO, 2003, p.3). A prática em jornalismo e as experiências em sala de aula deram subsídios para o professor escrever obras sobre o processo de produção jornalística. Um exemplo é o livro Métodos de Enseñanza de la Técnica del Periodismo (1963) elaborado a partir de suas "[...] experiências pedagógicas que vivenciou na preparação de jornalistas profissionais, convertendo-as em livro publicado pelo CIESPAL Centro Internacional de Estudios Superiores de Periodismo para América Latina [...]" (MELO, 2003, p. 6).

O pesquisador passou a defender, desde a década de 1950, a importância da formação acadêmica para um melhor desempenho no jornalismo, desenvolvimento da profissão e liberdade de imprensa. Duarte (2006) ressalta que tratava-se de uma proposta inovadora demais para uma época em que ser jornalista era somente um complemento para a renda. Mesmo diante da percepção da maioria dos profissionais ao verem o Revista Pauta Geral-Estudos em Jornalismo, Ponta Grossa v.5, n.2, p. 24-40, Jul/Dez 2018. 
jornalismo como profissão desacreditada, Beltrão preocupava-se "[...] em sistematizar informações e disseminá-las de maneira a tornar a informação dos meios de comunicação de massa mais próximos da sociedade" (DUARTE, 2006, p. 26).

$\mathrm{Na}$ entrevista publicada na Revista Brasileira de Ciências da Comunicação, ele explica as motivações iniciais pelo interesse nos estudos e ensino do jornalismo. Uma percepção da relevância de conciliar a prática com a teoria para tornar o jornalismo um instrumento a favor da sociedade. Nesse sentido, o pesquisador passa a incentivar a formação de jornalistas.

\begin{abstract}
Um belo dia, o Aníbal Fernandes, diretor do jornal, apareceu na redação com um livro de cor cinza, francês, que se chamava: Como fazer um jornal. Eu nunca tinha imaginado na minha vida que se pudesse aprender a fazer Jornalismo de outro modo, senão fazendo o próprio jornal. Este momento marcou demais a minha vida porque daí em diante eu passei a querer organizar uma biblioteca também. Eu comecei a perceber que era preciso estudar Jornalismo para poder fazer jornalismo. Esse foi o princípio do meu interesse pelo ensino do Jornalismo. (CANDENGUE, et al., 1987, p. 8)
\end{abstract}

Beltrão elabora uma trilogia didática com instruções sobre a atuação jornalística através das obras $A$ imprensa informativa - Técnica da notícia e da reportagem no jornal diário (1969), Jornalismo interpretativo: filosofia e técnica (1976) e Jornalismo opinativo (1980). Segundo Melo (1985, p.67) são manuais "[...] construídos com sensibilidade educativa e competência profissional, ele traça um roteiro seguro e criativo para o aprendizado dos processos de informação da atualidade [...]".

Na sistematização sobre o campo jornalístico, através das publicações do autor, aponta-se para uma ação didático-pedagógica beltraniana, na tentativa de conscientizar os jornalistas da proeminência do jornalismo no desenvolvimento brasileiro. Os conceitos teóricos e as experiências do próprio teórico em veículos jornalísticos fazem parte das orientações, "[...] com o intuito de ensinar de maneira simples, porém, respaldada por conceitos teóricos-metodológicos, como se faz um jornalismo de verdade" (GURGEL, 2012, p. 105).

Em um momento da história do jornalismo em que a profissão era praticada por políticos e por intelectuais de diversos campos, Beltrão concebe e contribui para a formação de profissionais que possam atuar especificamente na produção jornalística. 


\section{Contribuição do teórico para a Teoria do jornalismo}

As especificidades do jornalismo, a verificação deste como uma área de estudo e o dilema entre teoria e prática fazem parte do marco inicial dos estudos sobre a Teoria do Jornalismo no Brasil a partir das concepções e investigações de Luiz Beltrão. Na década de 1960 ele publicou as obras Iniciação à Filosofia do Jornalismo (1960), Métodos de enseñanza de la técnica del periodismo (1963), Técnica de jornal: apostilas para a $1^{a}$ série do curso de jornalimo (1964) e A Imprensa informativa: técnica da notícia e da reportagem no jornal diário; na década seguinte escreveu Sociedade de massa: comunicação e literatura (1972) e Jornalismo interpretativo: filosofia e técnica (1976); e em 1980 publica Jornalismo opinativo, entre outras produções bibliográficas.

É primordial verificar as principais obras do autor nesse primeiro movimento de estudos sobre o jornalismo. Apresenta-se algumas compreensões sobre Iniciação à Filosofia do Jornalismo e a trilogia - jornalismo informativo, interpretativo e opinativo. Conforme pontua Gurgel (2012), Beltrão já trabalhava como jornalista quando passou pelas ditaduras de Vargas e a militar. Logo, é importante avaliar as proposições do teórico considerando o contexto histórico do início desses estudos.

As abordagens do pesquisador em Iniciação à Filosofia do Jornalismo, publicado em 1960, contêm reflexões e sistematizações quanto aos sentidos do jornalismo, as particularidades, objetivo e os agentes que atuam junto ao mesmo. Assim, Beltrão identifica o jornalismo enquanto uma representação a respeito do real e traz referências para seu público sobre o cotidiano, "É uma informação de fatos correntes, de acontecimentos registrados em qualquer setor da vida social” (BELTRÃO, 1992, p. 69).

Configura-se, para ele, como um ofício de enorme responsabilidade. E não se resumo a relatar fatos do cotidiano, não é apenas uma técnica ou a narração do habitual, mas tem grande importância social para se compreender a realidade, sobretudo, pela possibilidade de contribuir com os interesses públicos, ao cumprir com o seu papel social. A função do jornalismo, conforme o teórico, parte da denúncia de atos de corrupção, até a contribuição para uma campanha social.

De maneira enfática Beltrão (1992, p.33) afirma que "Entre todas as atividades humanas, nenhuma responde tanto a uma necessidade do espírito e da vida social quanto 
o jornalismo". Por não se dirigir a uma única pessoa, em essência é voltado para a coletividade, o interesse comum, temas que perpassaram o dia a dia da sociedade. Tratase de informações de acontecimentos da vida social.

Movendo-se nesse âmbito, o autor demarca as especificidades do campo com relação aos demais e acrescenta que a atualidade é uma característica dominante do jornalismo, acentua Beltrão citando Tristão de Ataíde.

A atualidade é o presente, o que ocorre sobre a marcha do tempo, o que sucede atualmente ou o que, havendo sucedido, atua sobre a consciência do hoje. $\mathrm{O}$ anterior pertence à história, não ao jornalismo que, por essência, vive sobre o momento, informando sobre o presente e fixando-o para o futuro. (BELTRÃO, 1992, p. 70 apud ATAÍDE, 1957)

Essas informações dos fatos correntes cumprem, em sua visão, a missão de transmitir conhecimentos e orientar a opinião pública. Para tanto, os profissionais que atuam no jornalismo, classificados por Beltrão (1992) como um dos agentes do jornalismo, são instrumentos adequados de que se valem os fatos para converter-se em notícia. Nesse sentido, compreende-se a preocupação e incentivo do autor para a formação acadêmica dos jornalistas.

O exercício jornalístico, segundo o pesquisador, está condicionado à liberdade e a responsabilidade na atuação profissional, calcada no saber específico dos profissionais, nas condições históricas, na repercussão jurídica, ética e moral do fazer jornalístico. Beltrão (1992) destaca que: "Para realizar esse trabalho de primeiro plano, é convocado o jornalista, aquele que encontrou a sua vocação ao servir de porta-voz e interprete dos fatos sociais" (BELTRÃO, 1992, p. 147).

$\mathrm{Na}$ ausência do contato direto com a obra $A$ imprensa informativa (1969), adotemos as percepções de Vizeu (2007) em seus estudos sobre as contribuições das produções bibliográficas de Beltrão para os estudos e a Teoria do Jornalismo.

Trata-se de um manual crítico e didático sobre a informação no Jornalismo, resultado de dez anos de ensino e de 25 de prática jornalística de Beltrão. No livro, são tratados os vários aspectos que envolvem a produção da notícia como a linguagem jornalística, a função informativa do jornal e a notícia do jornal. Como em seus demais trabalhos, há preocupação constante entre a teoria e a prática do Jornalismo. Ao final de cada capítulo, além de uma bibliografia sobre o tema, Beltrão propõe exercícios práticos para serem desenvolvidos em sala de aula. (VIZEU, 2007, p. 29) 
O desenvolvimento dos meios de comunicação, em cada década, é compartilhado nas obras de Beltrão. A experiência da TV ao torna-se uma nova modalidade que veicula informações da atualidade para o público é avaliada pelo teórico na obra Jornalismo interpretativo: filosofia e técnica, lançada em 1976. No livro o autor também traça uma breve evolução do jornalismo, um trabalho artesanal que tornou-se profissão e com o invento de Gutenberg ganha força para adquirir aspectos industriais.

No desenvolvimento tecnológico a linguagem deve se adequar aos meios, na tentativa do público decodificar as mensagens. Deste modo, Beltrão (1976) elenca a configuração desse processo iniciado, como ele denomina, pelo grafojornalismo, através da escrita, cinejornalismo, radiojornalismo e o telejornalismo. Segundo o autor a narrativa jornalística a partir da informação audiovisual estabelece uma relação diferente com o público, capaz de interpretar e tecer comentários pelas imagens acompanhadas nos aparelhos televisivos. "De qualquer modo, deve o jornalismo à televisão o restabelecimento ou, pelo menos, o reconhecimento da capacidade de opinião e de ação do receptor massivo (BELTRÃO, 1976, p. 27).

No entanto, o autor critica a ausência de tempo no jornalismo televisivo para detalhar e investigar a fundo uma ocorrência, diferente do meio radiofônico. Apesar das notícias passarem a circular de maneira diferente, complementarem a informação radiofônica, pelo acesso a imagem, o público "Fica boiando, nadando na superfície; tão solicitada é pelo colorido e pelo sabor da novidade, que só de raro em raro mergulha na atualidade, penetra o íntimo e o secreto da situação do momento" (BELTRÃO, 1976, p. 38).

Em meio aos inúmeros fatos do cotidiano os agentes do jornalismo, segundo o teórico, independente do meio, tem a responsabilidade de executarem uma seleção crítica, e elaborarem as matérias que sejam realmente relevantes para o público. Esse trabalho é a interpretação jornalística.

Interpretação que é um exercício da inteligência e do discernimento de um agente qualificado, com excepcional aptidão para aprender toda a significação do fato para a comunidade, dentro de "um critério especial, de um juízo jornalístico que se resume em submeter o interesse particular e transitório para obter a universalidade e considerar, nos fatos, o seu valor permanente". (BELTRÃO, 1976, p. 47) 
Ultrapassar a interpretação jornalística com aspectos opinativos, acende o gênero opinativo. O pesquisador, na obra Jornalismo Opinativo, de 1980 , destaca as funções da opinião no campo jornalístico. No que se refere ao conceito de opinião, Beltrão (1980, p. 14) discorre que trata-se de uma função psicológica, pelo qual exprime-se um juízo quanto a um determinado fato, ideia ou situação. $O$ autor elenca três categorias específicas de opinião veiculadas pelo jornalismo, são elas: a opinião do editor, do jornalista e do leitor. Opiniões que geram a opinião pública.

As editorias e a linha editorial de um jornal são as vias para a expressão da opinião do editor. A tribuna do jornal, é um espaço propício para a empresa manifestar seu posicionamento quanto aos fatos sociais. A elaboração desse texto fundamenta-se em alguns critérios, tais como: a filosofia do grupo, relações com o tema em pauta, resultados de pesquisas que tem ligação com interesses da empresa; interesses econômicos e a experiência dos chefes de redação (BELTRÃO, 180, p. 19).

A opinião do jornalista é indicada como o juízo manifestado nas matérias e no cargo exercido. Os artigos, crônicas e charges são os espaços indicados para a manifestação da opinião desses agentes. No que se relaciona à audiência tem-se a opinião do leitor revelada pelas cartas, respostas de enquetes, retornos pela compra ou não do impresso, as escolhas políticas, entre outras indicações quanto ao concordar ou não com o material veiculado pelo editor e jornalista. A constatação de um público ativo e atento as mensagens veiculadas.

"Se um indivíduo é analfabeto, como é que ele se informa? Se não vai ao cinema e se ele não tem televisão, como é que ele intercambia opinião?" (CANDENGUE, et al., 1987, p. 13), a partir de percepções como essa Luiz Beltrão inicia os estudos de Folkcomunicação. Para o autor os meios de comunicação tradicionais não são os únicos canais de comunicação da população e tão pouco espaços exclusivos para a manifestação da opinião pública.

Daí eu me lembrei dos meus companheiros gráficos, me lembrei de um que era presidente do Lenhador de Recife, clube de frevo, me lembrei a história de Lampião, de Antônio Silva e de todos os bandoleiros de Pernambuco, eu tinha contato com os coronéis a mesma voracidade com que os usineiros substituíram os senhores de engenho na indústria do açúcar. Aí então eu comecei a reconsiderar tudo isso e comecei a apanhar esses dados. Aí eu chamei isso de folkcomunicação jornalística. Posteriormente, houve uma modificação. Acontece que eu vi que a função da Comunicação não estava somente em informar ou orientar, 
estava também em educar, havia uma função educativa, uma função diversional e havia uma função promocional. (CANDENGUE, et al., 1987, p. 13)

Uma leitura diferenciada que traça um diálogo com as classes marginalizadas, ressignifica o folclore enquanto uma expressão que deve ser vista além da superficialidade. Uma noção do que é a informação a partir da linguagem e expressão popular. Trata-se de um jornalismo na perspectiva de folkcomunicação, um exemplo é abordado no texto de Beltrão denominando o Ex-voto, presente no livro Folkcomunicação: teoria e metodologia (2004), para o autor um ex-voto ${ }^{4}$ é como um veículo jornalístico ao transmitir mensagens pelos objetos, desenhos, fotografias, cartas, entre outros, de acontecimentos como acidentes, náufragos, enfermidades, também servem de verificações das mazelas sociais. Portanto, a compreensão e expressão do povo quanto aos problemas vividos (BELTRÃO, 2004).

A respeito das compreensões do teórico quanto ao jornalismo interiorano destaca-se o artigo 0 jornalismo interiorano a serviço da comunidade, um texto que compõe a obra organizada por Francisco de Assis (2013), Imprensa do interior: conceitos e contextos. Nele o jornalismo interiorano é considerado por Beltrão (2013) a voz jornalística da "nossa cidade". Na concepção do autor, a população interessada em assuntos internacionais, nacionais e estaduais facilmente terá acesso a esses conteúdos, ao verificar um produto da grande mídia, mas os acontecimentos da região e da localidade, provavelmente, só terão espaço na mídia regional ou local.

"É instrumento de comunicação social e meio de liderança social, através do jornalista que se faz um líder autêntico" (BELTRÃO, 2013, p. 34), esse é um dos itens listados pelo autor na indicação da proeminência da função social da mídia local.

\footnotetext{
${ }_{4}^{4}$ Ex-voto é uma prática religiosa em que os fiéis oferecem os votos em formas de imagens esculpidas em madeira, argila, cera, pinturas, desenhos, cartas, entre outros formatos. Votos depositados em diferentes locais de peregrinação e devoção. O texto Ex-voto como um veículo jornalístico é o artigo veiculado na primeira edição da revista Comunicação e Problemas.
} 2018. 


\section{Percepções de outros teóricos quanto as investigações de Beltrão}

O teórico estudado no artigo recebe títulos de pioneiro, um homem à frente de seu tempo, um senhor do mundo, citado em diversos estudos. Portanto, é importante pontuar as ponderações de outros estudiosos do campo do jornalismo quanto as contribuições de Beltrão, por compreender que as pesquisas iniciais do autor também colaboraram para a qualificação desse campo.

Ao pesquisar sobre a vida e obra de Beltrão para a tese defendida em 1993, ter acesso ao escritório pessoal do teórico, familiares e conhecidos, Fátima Feliciano (2008), após compreender os estudos do autor temia que ele fosse notório somente pela sua Teoria da Folkcomunicação, e não fosse reconhecido pelos demais também pelas contribuições para o jornalismo e a comunicação. De certo modo as previsões da pesquisadora se concretizaram, atualmente Beltrão é mais estudado entre os pesquisadores de Folkcomunicação do que em Teoria do Jornalismo, porém vários estudiosos relembram do trabalho precursor feito por ele.

A perspectiva da autora aborda a ótica de Beltrão a partir de um profissional que parte de uma visão de dentro dos veículos de comunicação para fora, ele conhecia "[...] todos os meandros de um jornal - da importância de uma boa revisão sobre um bom texto, à importância de uma boa pesquisa, que embasasse esse mesmo bom texto [...]" (FELICIANO, 2008, p.3). A autora relembra que trata-se de um momento em que a produção jornalística ainda não se beneficiava da utilização de computadores.

"Eu costumo dizer sempre que o meu trabalho tem sido todo abrindo picadas para que outros aqueçam o caminho" (CANDENGUE, et al., 1987, p. 14). A proposição do jornalista foi seguida por alguns alunos que na época acompanhavam suas aulas e investigações, bem como por outros pesquisadores. Cita-se Marques de Melo como um dos mais proeminentes na área a perpetuar as ideias de Beltrão. Melo (2003) destaca o pioneirismo do teórico em reflexões relevantes para os estudos em jornalismo.

Vizeu (2007, p.29) compartilha da visão de Melo no que se refere a Beltrão e os estudos de gênero jornalísticos, "[...] o critério adotado por Beltrão sugere a separação dos gêneros segundo as funções que desempenham junto ao público leitor: informar, explicar e orientar, características que estão presentes na sua definição sobre Jornalismo". Para o autor, o teórico em estudo, foi o primeiro a elaborar um esboço de uma Teoria do Jornalismo no país pela pesquisa organizada com análises, conclusões e 
conceitos sobre o jornalismo, em estudos sobre a prática e teoria desse campo. Segundo Vizeu (2007), Beltrão foi o primeiro pesquisador brasileiro a se preocupar com a sistematização e a categorização para os gêneros em: jornalismo informativo, jornalismo interpretativo e jornalismo opinativo.

Ao abordar sobre as metodologias de pesquisa em jornalismo, Machado (2010, p.16) relembra que o primeiro projeto de pesquisa realizada pelo Instituto de Ciências da Informação, fundado por Beltrão, abordou estudos quanto aos "reflexos da falta de jornais diários no Recife durante a greve dos gráficos" e "reportagem policial nos jornais de Recife". Assim, "Marques de Melo, que participou como assistente de Beltrão, considera este caso como a primeira atividade regular de iniciação científica em Jornalismo no país" (MACHADO, 2010, p. 16).

Inovador acadêmico, evidencia Duarte (2006) quando cita que Beltrão gostava de discutir sobre jornalismo e logo que pôde deixou as redações pelo ensino. $O$ autor prossegue apontando as relações do jornalismo com a folkcomunicação.

A noção desse tipo de comunicação leva, ainda, à descoberta, no cantador popular, no artista da periferia, não apenas de um produtor cultural, mas informante referencial, que se caracteriza inclusive como realizador da ação jornalística. [...] O artesão, por exemplo, seria uma espécie de folkjornalista, ao selecionar informações do ambiente em que vive e retransmitir aquilo que faz sentido para seu público, mantendo a unidade no grupo. (DUARTE, 2006, p. 28)

Esses são apenas alguns dos estudiosos que analisaram as investigações jornalísticas de Beltrão. Reconhecem seus estudos na demarcação inicial de um espaço propício para as discussões quanto ao exercício do jornalismo e sua importância social.

\section{Considerações finais}

Conforme Gadini (2005), é necessária a tradição de estudos e estratégias metodológicas capazes de legitimar e fortalecer o campo jornalístico. Nessa perspectiva, verifica-se que os estudos de Luiz Beltrão relacionados ao jornalismo constituem-se como as primeiras iniciativas para a constituição de uma Teoria do Jornalismo. O teórico foi o primeiro a ver o jornalismo, no Brasil, como uma área de estudo e analisar os dilemas entre teoria e prática. 
$\mathrm{Na}$ condição de jornalista, passou pelas ditaduras de Vargas e a militar em 1964. Pernambucano, vivenciava as problemáticas sociais do Nordeste. Conforme ele mesmo mencionou, durante a entrevista para a Revista Brasileira de Comunicação, os aprendizados na Faculdade de Direito do Recife estavam, sobretudo, nas discussões com os colegas de turmas, conscientes das dificuldades da época, faziam política na medida do possível, em meio as repressões.

O professor, jornalista, escritor, sindicalista, pesquisador, tem a realidade como referências de seus trabalhos. Concebia a importância do jornalismo dialogar com a sociedade e desse entendimento para compreendê-la. A partir da referência ao cotidiano, o teórico passa a olhar e sistematizar os aspectos de um ponto de vista teóricometodológico e pensar em realidades próprias para o campo jornalístico.

Suas abordagens refletem questões do jornalismo. Para ele, o jornal ocupava um local de orientação, a base do jornal está na formação. Por sua vez, o jornalista é o agente de informação, responsável por transmitir o que é significativo para a comunidade. Oferecer ao público o que é importante para ele ler e para a formação da opinião pública.

A atualidade é apontada enquanto uma característica central do jornalismo. pesquisador formula as categorias de gêneros informativo, interpretativo e opinativo. Atribui ainda a formação acadêmica a possibilidade para liberdade de imprensa. Assim, o pesquisador avança em teorizar a prática jornalística.

Na década de 1960, momento em que pouco se pensava academicamente sobre o jornalismo, Beltrão, que não tinha uma formação específica na área, estimulou o ensino em jornalismo, para compreender o local do profissional, a responsabilidade da profissão e pensar em construir os objetos de estudos voltados para as questões jornalísticas. Um modo de aprender sobre o jornalismo de maneira sistematizada diante da necessidade de formação superior.

O Instituto de Ciências da Informação (ICINFORM) e a revista Comunicação e Problema surgem, por incentivo do pesquisador, como espaços para refletir essas questões do jornalismo, estudar os objetos do campo jornalístico, demarcar um local para pesquisas nessa área e ser um ambiente possível para organizar os artigos.

Da mesma maneira, o escritor acreditava que o folclore também deve ser analisado como uma manifestação comunicativa. Objetos de pesquisa que estão longe dos veículos hegemônicos e que merecem ser estudados. Ao verificar que as 2018. 
contribuições da folkcomunicação para o jornalismo é instrumentalizá-lo para as classes subalternas.

Pesquisadores da área resgatam a ousadia intelectual de Beltrão pela trajetória de pesquisas, por ter sido o primeiro doutor em Comunicação conquistado em universidade brasileira e pelas iniciativas em demarcar espaços de investigações sobre o jornalismo. Um trabalho reconhecido pela designação do prêmio anual Luiz Beltrão de Ciências da Comunicação, entregue durante o evento nacional da Intercom para pesquisadores que se destaca na pesquisa (MELO 2003; GOBBI 2005)

É notório o movimento inicial do teórico e suas contribuições para a Teoria do Jornalismo. Inicialmente preocupado em reconhecer as características do jornalismo (atual, explicativo e orientador), e a relevância para a sociedade.

\section{Referências}

BELTRÃO, Luiz. Iniciação à Filosofia do Jornalismo. 2. ed. São Paulo: Editora da Universidade de São Paulo; Com-arte, 1992.

. Jornalismo opinativo. 2. ed. AalPorto Alegre: Sulina, 1980.

. Jornalismo interpretativo: filosofia e técnica. Porto Alegre: Sulina, 1976.

. A greve dos desempregados. São Paulo: Cortez, 1984.

UMESP, 2004.

Folkcomunicação: teoria e metodologia. São Bernardo do Campo:

. O jornalismo interiorano a serviço da comunidade. In: ASSIS, Francisco de (Org.). Imprensa do interior: conceitos e contextos. Chapecó: Argos, 2013.

CADENGUE, Rogério Bastos, et al. Luiz Beltrão: a folkcomunicação não é uma comunicação classista. Intercom - Revista Brasileira de Comunicação, edição $n^{\circ} 57$, v. 10, $1987 . \quad$ Disponível em: <http://portcom.intercom.org.br/revistas/index.php/revistaintercom/article/view/1513/1492> Acesso em: 09 de dezembro de 2018.

DIAS, Eliane Penha Mergulhão. Marcas folkcomunicacionais na obra literária de Luiz Beltrão. Tese (Doutorado em Comunicação Social) - Universidade Metodista de São Paulo, São Bernardo do Campo, 2008.

DUARTE, Jorge. O jornalismo sai das ruas para ingressar na universidade. Revista Continente, ano V, $\mathrm{n}^{\circ}$ 50, 2006. 
FELICIANO, Fátima. Luiz Beltrão: um senhor do mundo ... do jornalismo ... da comunicação .... e, por quê não, da Folkcomunicação. In: $6^{\circ}$ Encontro Nacional da Rede Alfredo de Carvalho, Niterói - RJ, 2008. Disponível em: $<$ http://www.ufrgs.br/alcar/encontros-nacionais-1/encontros-nacionais/6o-encontro-20081/Luiz\%20Beltrao.pdf> Acesso em: 13 de janeiro de 2018.

GADINI, Sérgio Luiz. Dilemas da Pesquisa no Jornalismo Contemporâneo: da abrangência midiática à ausência de métodos específicos de investigação. Trabalho apresentado no III Encontro Nacional de Pesquisadores em Jornalismo 27 a 29 de Novembro de 2005. Florianópolis / Sc. Disponível em: <http://sbpjor.kamotini.kinghost.net/sbpjor/admjor/arquivos/iiisbpjor2005_-_ci__sergio_luiz_gadini.pdf>. Acesso em: 15 de janeiro de 2018.

GOBBI, Maria Cristina. O legado Pioneiro de Luiz Beltrão. In: III Encontro Nacional da Rede Alfredo de Carvalho, Novo Hamburgo - RS, 2005. Disponível em: $<$ www.ufrgs.br/alcar/.../O\%20legado\%20Pioneiro\%20de\%20Luiz\%20Beltrao.doc> Acesso em: 10 de janeiro de 2018.

GURGEL, Eduardo Amaral. A pedagogia do jornalismo na teoria e prática de Luiz Beltrão. Dissertação (Mestrado em Comunicação Social) - Universidade Metodista de São Paulo, São Bernardo do Campo, 2012.

HOHLFELDT, Antonio; VALLES, Rafael Rosinato. Conceito e história do Jornalismo brasileiro na "Revista de Comunicação". Porto Alegre: EDIPUCRS, 2008. Disponível em: <http://www.pucrs.br/edipucrs/conceitoehistoria.pdf> Acesso em: 10 de janeiro de 2018.

MACHADO, Elias. Dos estudos sobre o jornalismo às teorias do jornalismo: Três pressupostos para a consolidação do jornalismo como campo de conhecimento. Revista da Associação Nacional dos Programas de Pós-graduação em Comunicação, edição 1, em dezembro de 2004. Disponível em: <http://www.compos.org.br/seer/index.php/ecompos/article/viewFile/2/4> Acesso em: 12 de janeiro de 2018.

MELO, José Marques de. Luiz Beltrão: pioneiro dos estudos de Folkcomunicação no Brasil. Disponível em: <http://www.bocc.ubi.pt/pag/melo-marques-LUIZ-BELTRAO.pdf> Acesso em: 10 de janeiro de 2018.

- Trajetória Pedagógica de Luiz Beltrão. Intercom - Revista Brasileira de Ciências da Comunicação, edição $n^{0} 53$, v.8, n.1, 1985. Disponível em: $<$ http://portcom.intercom.org.br/revistas/index.php/revistaintercom/article/view/1272/> Acesso em: 10 de janeiro de 2018.

VIZEU, Alfredo. Beltrão, os estudos e as teorias do Jornalismo. Intercom - Revista Brasileira de Ciências da Comunicação, edição $n^{\circ}$ 1, v.30, n.1, jan./jun. 2007. Disponível em: <http://portcom.intercom.org.br/revistas/index.php/revistaintercom/article/view/278> Acesso em: 10 de janeiro de 2018. 
WANDERLEY, Elvis. Luiz Beltrão: de Olinda para o mundo. Revista PJ:Br - Jornalismo Brasileiro, edição $1^{\circ}$, primeiro semestre, 2003. Disponível em:

< http://www2.eca.usp.br/pjbr/arquivos/monografia1_f.htm> Acesso em: 08 de janeiro de 2018.

Recebido em: 12/06/2018

Publicado em: 21/12/2018 